\title{
Impact of beverage consumption, age, and site dependency on dual energy X-ray absorptiometry (DEXA) measurements in perimenopausal women: a prospective study
}

\author{
Huan-Chu Lo ${ }^{1,2,3}$, Duen-Pang Kuo ${ }^{1}$, Yen-Lin Chen ${ }^{1}$
}

\author{
${ }^{1}$ Department of Radiology, Taoyuan Armed Forces General Hospital, Taoyuan, Taiwan, \\ China \\ ${ }^{2}$ Department of Diagnostic Radiology, National Defense Medical Center, Triservice \\ General Hospital, Taipei, Taiwan, China \\ ${ }^{3}$ Department of Radiology, Koo Foundation Sun Yat-Sen Cancer Center, Taipei, Taiwan
}

Submitted: 12 March 2015

Accepted: 18 May 2015

Arch Med Sci 2017; 13, 5: 1178-1187

DOI: https://doi.org/10.5114/aoms.2017.66033

Copyright (c) 2017 Termedia \& Banach

\section{Abstract}

Introduction: The aim of this study was to determine the best site for bone mineral density (BMD) measurements based on $T$-scores, age, and beverage consumption.

Material and methods: In this prospective study, 271 women stratified by age (average age: 61.9 years) underwent dual energy $\mathrm{X}$-ray absorptiometry (DEXA) scanning of their lumbar spine, hips, and forearms. Osteoporosis was defined as a BMD of 2.5 standard deviations or more below the mean peak bone mass based on a reference population of adult women (translated as a $T$-score $\leq-2.5)$, as measured by DEXA. Participants were also evaluated regarding alcohol and caffeine consumption by a semiquantitative questionnaire.

Results: A significant discrepancy was observed in the classification of osteoporosis at different locations, with hip and forearm showing the best correlation (Pearson's $r=0.627, p<0.001$ ). In addition, for participants over 50 years of age, hip and forearm showed the best correlation. Significant correlations were also noted between forearm $T$-scores and caffeine consumed and, to a lesser extent, the level of alcohol consumption. In the group $\leq 50$ years of age, lumbar spine and forearm $T$-scores were only associated with alcohol consumption. In the group over 50 years of age, hip and forearm $T$-scores were only associated with caffeine consumption.

Conclusions: Bone mineral density measurements at the hip and forearm correlated with caffeine consumption in elderly Taiwanese women. This is an important finding since age and caffeine consumption are known risk factors for osteoporosis.

Key words: bone mineral density, dual-energy X-ray absorptiometry, osteoporosis, osteopenia, caffeine consumption, alcohol consumption.

\section{Introduction}

Osteoporosis is characterized by microarchitectural deterioration and a decrease in bone mass leading to an increased risk of fracture [1]. Osteoporotic fractures are often due to decreased bone mineral density (BMD) and dual-energy X-ray absorptiometry (DEXA) is the

\author{
Corresponding author: \\ Huan-Chu Lo \\ Department of Radiology \\ Taoyuan Armed \\ Forces General Hospital \\ No. 168, Chong-Sing Road \\ Tao-Yuan 325, Taiwan \\ China \\ Phone: 886-3-4799595 \\ ext. 325502 \\ Fax: 886-3-4090765 \\ E-mail: worenlo@ms46.hinet. \\ net
}


most commonly used method of BMD evaluation. The strengths of DEXA are its low radiation dose (1-6 $\mu \mathrm{Sv})$ and rapid scanning time (1-2 min) providing an 'areal' BMD $\left(\mathrm{g} / \mathrm{cm}^{2}\right)$ of integral (cortical and cancellous) bone [2-5].

It is well known that beverage habits influence $B M D$, including excessive alcohol intake and tea consumption [6-12]. Coffee and tea are among the most common sources of dietary caffeine intake. Several epidemiological studies have shown that high dietary caffeine intake is associated with reduced $B M D$ and increased urinary calcium loss $[8,13]$. In addition, both alcohol and caffeine have been implicated in the development of osteoporosis in patients at risk $[11,13,14]$. These factors are associated with an increased risk of hip fracture $[6,15]$. Risk factors for osteoporosis and subsequent fractures, especially hip fractures, also include sedentary lifestyle [7, 16] and smoking [17], as well as VEGF levels [18], and leptin levels [19].

According to the World Health Organization (WHO) [2], osteoporosis is defined as a BMD of 2.5 standard deviations or more below the mean peak bone mass of a reference population of young, healthy adult women (translated as a $T$-score), as measured by DEXA. These measurements are usually performed at the proximal femur, lumbar spine, and distal third of the radius, and the diagnosis of osteoporosis is made when the T score is $\leq-2.5[2-5]$.

However, BMD measurements have been shown to vary based on the site measured [20]. In particular, increased calcification within the laminae and facet joints and increased development of vascular calcifications, spondylophytes and endplate sclerosis can render DEXA scanning of the lumbar spine unreliable [21, 22].

The aim of this study, therefore, was to determine the best site for BMD measurement in elder- ly Taiwanese women by correlating $T$-scores with age and beverage consumption.

\section{Material and methods}

\section{Participants}

All participants gave their written informed consent prior to participation in the study including their agreement to have serial BMD measurements. This prospective study was approved by the Institutional Review Board of our hospital.

A total of 271 women with an average age of $61.9 \pm 12.7$ years (range, 19 to 93 years; Table I) were consecutively enrolled over a 6-month period. The participants were referred to our department by open announcements of BMD assessment posted at various departments and outpatient clinics throughout the hospital. According to their personal and medical history, participants with known pre-existing bone diseases such as tumor, metastases, or metabolic bone disorders (including diabetes or endocrine conditions) were excluded from the study. Participants with prior fractures were also excluded.

Each participant was evaluated by history and physical examination using a self-reported questionnaire. Data consisting of participant's age, height, weight and history were recorded. The medical history was also obtained during direct participant interview and included estrogen replacement therapy, menopausal status, use of bone-remodeling agents, and presence of related diseases.

\section{DEXA scans and reliability of bone mineral density (BMD) measurements}

Bone mineral density data were obtained using a DEXA scanner (QDR-4500w; Hologic, Waltham, MA, USA). Bone mineral density measurements $\left(\mathrm{g} / \mathrm{cm}^{2}\right)$ were taken at the first through fourth lum-

Table I. Participant demographics and descriptive statistics for 271 participants

\begin{tabular}{|c|c|c|c|}
\hline Participant characteristics & Overall $(n=271)$ & $\leq 50$ years old $(n=38)$ & $>50$ years old $(n=233)$ \\
\hline Age [years] ${ }^{1}$ & $61.0(53.0-70.0)$ & $44.5(38.5-49.0)$ & $63.0(57.0-72.0)$ \\
\hline Height $[\mathrm{cm}]^{1}$ & $155.0(150.0-160.0)$ & $159.5(155.0-163.0)$ & $154.0(150.0-158.0)$ \\
\hline Weight $[\mathrm{kg}]^{1}$ & $55.0(50.0-62.0)$ & $56.5(50.8-65.0)$ & $55.0(50.0-62.0)$ \\
\hline BMI $\left[\mathrm{kg} / \mathrm{m}^{2}\right]^{2}$ & $23.6 \pm 3.6$ & $22.9 \pm 3.8$ & $23.8 \pm 3.6$ \\
\hline Lumbar (L1-L4) T-score ${ }^{2}$ & $-2.118 \pm 1.235$ & $-1.047 \pm 0.986$ & $-2.293 \pm 1.184$ \\
\hline Hip T-score ${ }^{2}$ & $-1.766 \pm 1.103$ & $-0.989 \pm 1.014$ & $-1.892 \pm 1.066$ \\
\hline Forearm $T$-score ${ }^{2}$ & $-1.291 \pm 1.455$ & $0.205 \pm 0.894$ & $-1.535 \pm 1.382$ \\
\hline Alcohol consumed ${ }^{3}$ & $19(7.0)$ & $3(7.9)$ & $16(6.9)$ \\
\hline Caffeine consumed ${ }^{3}$ & $130(48.0)$ & $28(73.7)$ & $102(43.8)$ \\
\hline
\end{tabular}

Values are expressed as ${ }^{1}$ median $(I Q R),{ }^{2}$ mean $\pm S D,{ }^{3}$ number (percentage). BMI-body mass index, IQR - interquartile range, SD - standard deviation. 
bar vertebrae, the hip (femoral neck, trochanteric region and intertrochanteric region) and the distal one-third of the radius. After completion of DEXA scanning, BMDs as well as T-scores for individual lumbar vertebrae (L1-L4), hip, and forearm were calculated using on-line software. These measurements comprised our data comparison pool.

Serial scans were performed on the same day and reports were confirmed and classified by an experienced radiologist (H.C.L.). According to the WHO, a $T$-score less than -2.5 was indicative of osteoporosis. Osteopenia denotes bone loss in the range of -1 to -2.5 . Participants with an average $T$-score above -1 were considered healthy [2].

In our study, the BMD measurements revealed no significant differences between test-retest and between operators, except for total mass. With coefficients of variation ranging from $0.2 \%$ to $3.5 \%$, and with intraclass correlation coefficients ranging from 0.99 to 1.00 , the Hologic QDR 4500/A DXA system was shown to be highly reliable regarding BMD assessment [23].

\section{Beverage consumption and semiquantitative beverage-frequency questionnaire}

The consumption of the three varieties of beverages most widely imbibed throughout the world (alcohol, coffee, and tea) was evaluated using a modified and validated self-administered beverage frequency questionnaire [12, 13]. Participants were asked to report their average alcohol, coffee and tea consumption per day during the previous year. According to the International Osteoporosis Foundation's suggestion, alcohol consumption was regarded as positive if the participant consumed more than $500 \mathrm{ml} /$ day of beer (4\% alcohol), $160 \mathrm{ml} /$ day of wine $(12.5 \%$ alcohol), or $50 \mathrm{ml} /$ day of hard liquor ( $40 \%$ alcohol). In other words, consumption of alcohol in excess of the safe drinking limit of more than 2 units a day

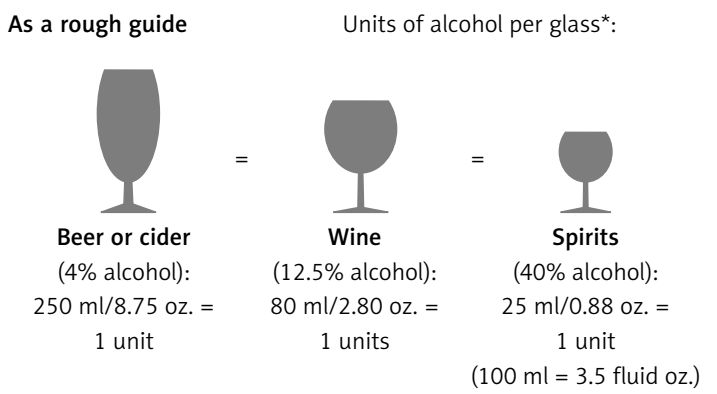

Figure 1. Units of alcohol per glass as a rough guide for the amount of alcohol consumed in beer (or cider), wine, and hard liquor by the glass

* Standard glasses and alcohol content in beverages vary per country, hence fluid amounts and percentages used rather than standard glasses.
(Figure 1) is regarded as positive, where a unit of alcohol is equivalent to $10 \mathrm{ml}$ (or approximately 8 grams) of pure ethanol, the active chemical ingredient in alcoholic beverages. Excessive alcohol consumption increases the risk of osteoporosis and fractures [24].

Coffee consumption was regarded as positive if the participant consumed more than 2 units of caffeine/day (one cup of coffee was regarded as 1 unit of caffeine containing $136 \mathrm{mg}$ ). Tea consumption was regarded as positive if the participant consumed more than 4 cups/day of tea (with one cup of tea regarded as 0.5 unit of caffeine) $[12,13]$.

The participants were also asked questions regarding their alcohol, tea, and coffee-drinking habits and were then categorized as habitual vs. nonhabitual drinkers on the basis of self-report. Participants who drank coffee or tea more than three times per week for 6 months or longer were recorded as habitual drinkers; otherwise, they were classified as nonhabitual drinkers. In terms of alcohol consumption, participants were classified as habitual drinkers if they drank alcohol at least once a week $[12,13]$.

\section{Statistical analysis}

Age, height, and weight of each patient were considered non-normally distributed continuous variables and represented by median and inter-quartile range $(I Q R$, the range between the $25^{\text {th }}$ and $75^{\text {th }}$ percentile). $T$-scores of lumbar spine, hip, and forearm were normally distributed and represented as means and standard deviations (SDs). Categorical variables were represented by counts and percentages. In order to adjust for the effect of age, participants were divided into 2 groups: women $\leq 50$ years of age vs. women $>50$ years of age.

Differences in $T$-scores at the lumbar spine, hip, and forearm were compared by paired $t$-test. Pearson's correlation coefficient $r$ (Pearson's $r$ ) was used to determine the associations between the $T$-score among the three sites, and the point biserial coefficient $r$ was used to determine the associations between $T$-scores and types of beverages consumed as the beverages consumed represented categorical data [25]. Cohen's $\kappa$ was used to compare the reliability of diagnostic agreement among the three sites. All statistical assessments were two-sided and evaluated at the 0.05 level of significant difference. Statistical analyses were performed using SPSS software version 18.0 (SPSS Inc., Chicago, IL, USA).

\section{Results}

Demographic data for the 271 participants are summarized in Table I. Their median age was 
61.0 years (IQR: $53.0-70.0$ years), median height was $155.0 \mathrm{~cm}$ (IQR: $150.0-160.0 \mathrm{~cm}$ ), and median weight was $55.0 \mathrm{~kg}$ (IQR: $50.0-62.0 \mathrm{~kg})$. Their average body mass index (BMI) was $23.6 \pm 3.6 \mathrm{~kg} / \mathrm{m}^{2}$. The average $T$-scores measured at the lumbar spine, hip, and forearm were $-2.118 \pm 1.235$, $-1.766 \pm 1.103$, and $-1.291 \pm 1.455$, respectively.

There were 38 participants $\leq 50$ years of age with a median age of 44.5 years (IQR: $38.5-49.0$ years), median height of $159.5 \mathrm{~cm}$ (IQR: 155.0$163.0 \mathrm{~cm})$, and median weight of $56.5 \mathrm{~kg}$ (IQR: $50.8-65.0 \mathrm{~kg})$. Their average BMI was $22.9 \pm 3.8$ $\mathrm{kg} / \mathrm{m}^{2}$. Their average $T$-scores measured at the lumbar spine, hip, and forearm were -1.047 $\pm 0.986,-0.989 \pm 1.014$, and $0.205 \pm 0.894$, respectively.

There were 233 participants over 50 years of age with a median age of 63.0 years (IQR: 57.072.0 years), a median height of $154.0 \mathrm{~cm}$ (IQR: $150.0-158.0 \mathrm{~cm}$ ), and median weight of $55.0 \mathrm{~kg}$ (IQR: $50.0-62.0 \mathrm{~kg}$ ). Their average BMI was 23.8 $\pm 3.6 \mathrm{~kg} / \mathrm{m}^{2}$. Their average $T$-scores measured at the lumbar spine, hip, and forearm were -2.293 $\pm 1.184,-1.892 \pm 1.066$, and $-1.535 \pm 1.382$, respectively.

Of the 271 women who participated in the study, 19 (7.0\%) consumed alcohol and 130 (48.0\%) participants consumed caffeine (coffee or tea). In the age group $\leq 50$ years of age, $3(7.9 \%)$ participants consumed alcohol and 28 (73.7\%) participants consumed caffeine. In the group over 50 years of age, 16 (6.9\%) consumed alcohol and $102(43.8 \%)$ participants consumed caffeine. The remaining 136 participants abstained from the consumption of alcohol or caffeinated beverages and drank only water.

Figure 2 is a graph of $T$-scores for lumbar spine, hip, and forearm sites. There were significant differences in the $T$-scores between lumbar spine and hip, lumbar spine and forearm, and hip and forearm (all $p<0.001$ ). Moreover, in the group over 50 years of age, there were significant differences in the $T$-scores between lumbar spine and hip, lumbar spine and forearm, and hip and forearm (all $p<0.001$, data not shown). On the other hand, there were significant differences only in the $T$-scores between lumbar spine and forearm and hip and forearm in the group $\leq 50$ years of age (both $p<0.001$, data not shown).

Figure 3 shows the correlations in $T$-scores among lumbar spine, hip, and forearm. There were significant correlations in $T$-scores between lumbar spine and hip (Pearson's $r=0.551, p<0.001$, Figure $3 \mathrm{~A}$ ), lumbar spine and forearm (Pearson's $r=0.583, p<0.001$, Figure $3 \mathrm{~B}$ ), and hip and forearm (Pearson's $r=0.627, p<0.001$, Figure $3 \mathrm{C}$ ), with the best correlation occurring between hip and forearm.
Moreover, in the group $\leq 50$ years of age, there were significant correlations in $T$-scores between lumbar spine and hip (Pearson's $r=0.611$, $p<0.001$ ), lumbar spine and forearm (Pearson's $r=0.417, p<0.001$ ), and hip and forearm (Pearson's $r=0.544, p<0.001$ ) (data not shown), with the best correlation observed between lumbar spine and hip.

In the group over 50 years of age, there were significant correlations in $T$-scores between lumbar spine and hip (Pearson's $r=0.489, p<0.001$ ), lumbar spine and forearm (Pearson's $r=0.522$, $p<0.001$ ), and hip and forearm (Pearson's $r=$ $0.592, p<0.001$ ) (data not shown), with the best correlation found between hip and forearm.

Table II displays the diagnostic agreement among lumbar spine, hip, and forearm with regards to $T$-score. The number of participants with the same diagnostic agreement in the three categories (normal, osteopenia, and osteoporosis) between lumbar spine and hip, lumbar spine and forearm, and hip and forearm were 135 (49.8\%) $(\kappa=0.236), 114(42.7 \%)(\kappa=0.161)$, and 149 $(55.0 \%)(\kappa=0.336)$, respectively, with hip and forearm showing the best correlation agreement.

In the group $\leq 50$ years of age, the number of participants with the same diagnostic agreement in the three categories (normal, osteopenia, and osteoporosis) between lumbar spine and hip was $21(55.3 \%)(\kappa=0.206)$, whereas the data were insufficient to access the diagnostic agreement in either lumbar spine and forearm or hip and forearm.

In the group over 50 years of age, the number of participants with the same diagnostic agreement in the three categories (normal, osteopenia, and osteoporosis) between lumbar spine and hip, lumbar spine and forearm, and hip and forearm were $114(48.9 \%)(\kappa=0.214), 98(42.1 \%)(\kappa=0.153)$, and $127(54.5 \%)(\kappa=0.326)$, respectively, with hip and forearm showing the best agreement.

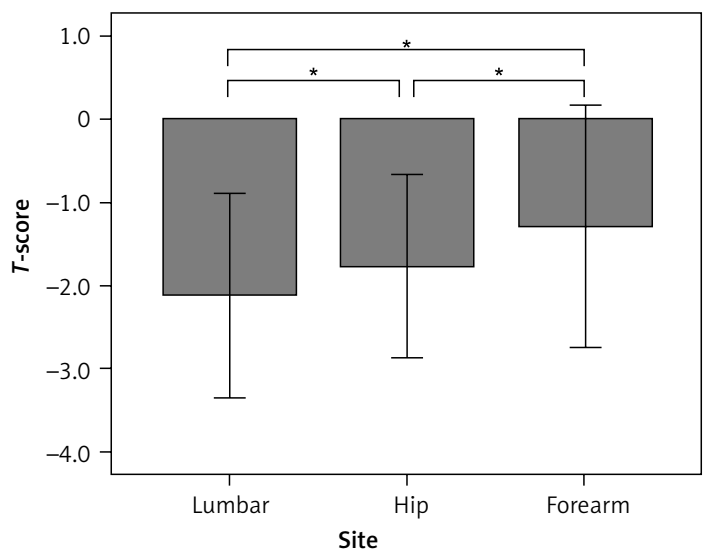

Figure 2. Graph of $T$-scores for lumbar spine, hip, and forearm sites

*Indicates significant difference between the two groups. 
A

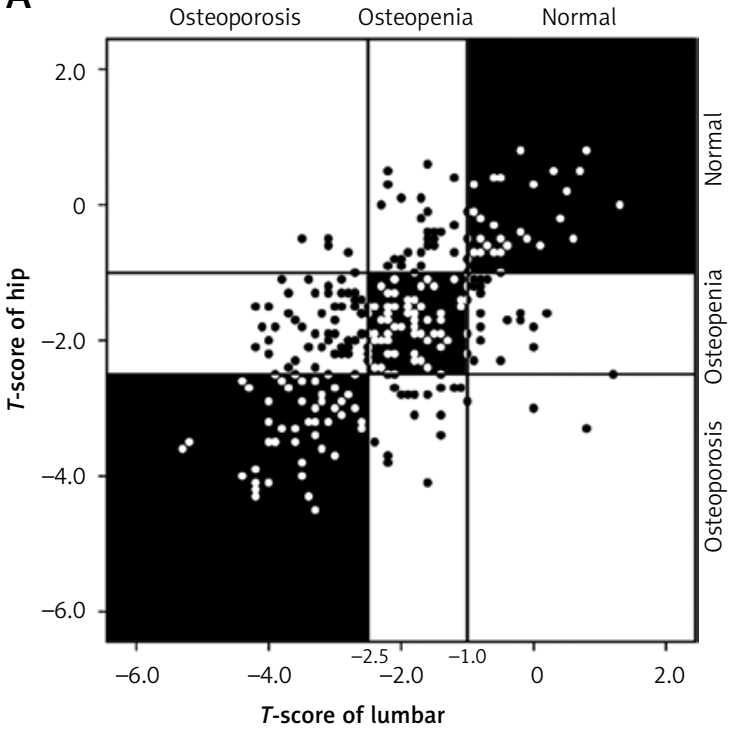

C

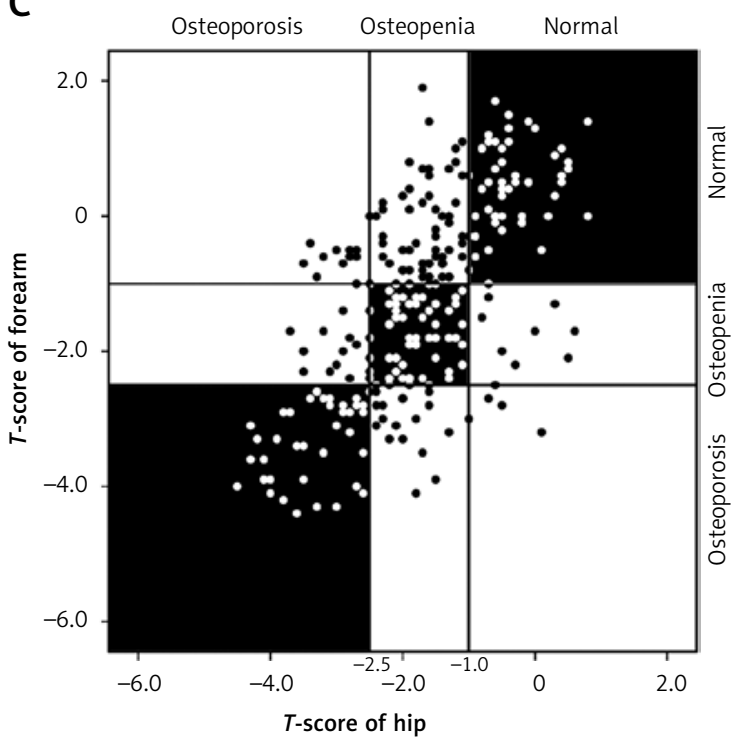

B

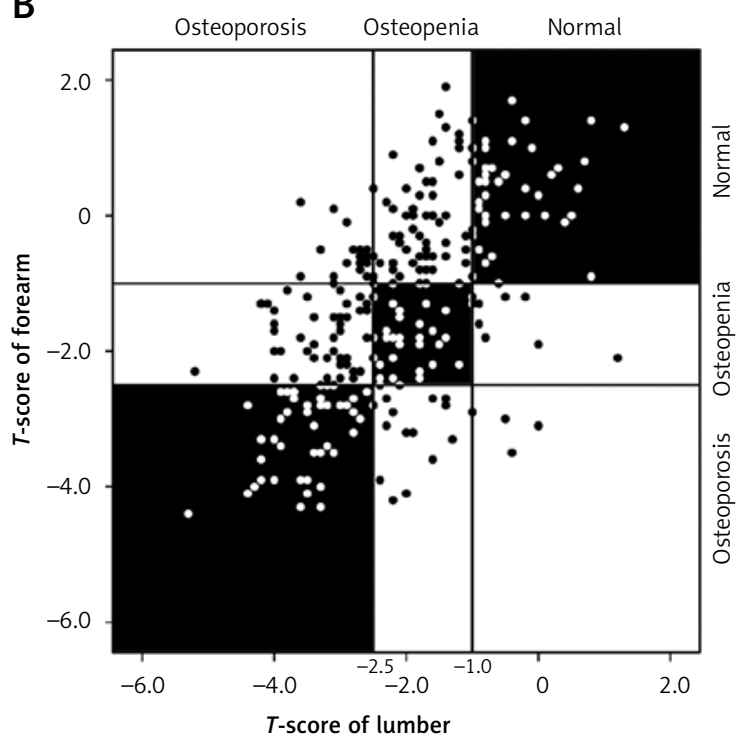

Figure 3. Correlations among $T$-scores for lumbar spine, hip, and forearm. The black area indicates the same category between the two sites
Table III shows the correlation between $T$-scores and the type of beverage consumed. The use of caffeine or alcohol correlated with $T$-scores to different extents in the lumbar spine, hip and forearm. Changes in hip and forearm $T$-scores appeared to be strongly associated with caffeine consumption (Table III). In contrast, lumbar spine was only associated with caffeine consumption and to a lesser extent than either forearm or hip.

A significant correlation was noted between $T$-scores of the forearm and caffeine consumption (point biserial coefficient $r=0.228, p<0.001$ ) and to a lesser extent the level of alcohol consumption (point biserial coefficient $r=0.135$, $p=0.027$ ). There was a significant correlation between $T$-scores of the hip and caffeine consumed (point biserial coefficient $r=0.226, p<0.001$ ) and to a lesser extent between T-score of the lumbar spine and caffeine consumed (point biserial coefficient $r=0.156, p=0.010$ ).

In the group $\leq 50$ years of age, lumbar spine and forearm were only associated with alcohol consumption (point biserial coefficient $r=0.325$, $p=0.046$ for lumbar spine and point biserial coefficient $r=0.330, p=0.043$ for forearm, respectively).

In the group over 50 years of age, hip and forearm were only associated with caffeine consumption (point biserial coefficient $r=0.178, p=0.006$ for hip and point biserial coefficient $r=0.176, p=$ 0.007 for forearm, respectively).

\section{Discussion}

This study correlated BMD measurements at different skeletal sites (lumbar spine, hip, and forearm) with age and beverage consumption 
Table II. Distribution of diagnostic agreement among lumbar spine, hip, and forearm. A - lumbar spine vs. hip, B - lumbar spine vs. forearm, C - hip vs. forearm

A

\begin{tabular}{|c|c|c|c|c|c|c|c|}
\hline \multirow[t]{3}{*}{ Hip } & \multicolumn{6}{|c|}{ Lumbar spine } & \multirow[t]{3}{*}{$\kappa$ value } \\
\hline & \multicolumn{2}{|c|}{ Normal } & \multicolumn{2}{|c|}{ Osteopenia } & \multicolumn{2}{|c|}{ Osteoporosis } & \\
\hline & $n$ & $\%$ & $n$ & $\%$ & $n$ & $\%$ & \\
\hline Overall: & 59 & 100 & 99 & 100 & 113 & 100 & \\
\hline Normal $(n=65)$ & 33 & 55.9 & 27 & 27.3 & 5 & 4.4 & 0.236 \\
\hline Osteopenia $(n=136)$ & 22 & 37.3 & 54 & 54.5 & 60 & 53.1 & \\
\hline Osteoporosis $(n=70)$ & 4 & 6.8 & 18 & 18.2 & 48 & 42.5 & \\
\hline$\leq 50$ years old: & 18 & 100 & 19 & 100 & 1 & 100 & 0.206 \\
\hline Normal $(n=20)$ & 12 & 66.7 & 8 & 42.1 & 0 & & \\
\hline Osteopenia $(n=14)$ & 6 & 33.3 & 8 & 42.1 & 0 & & \\
\hline Osteoporosis $(n=4)$ & 0 & & 3 & 15.8 & 1 & 100 & \\
\hline > 50 years old: & 41 & 100 & 80 & 100 & 112 & 100 & \\
\hline Normal $(n=45)$ & 21 & 51.2 & 19 & 23.8 & 5 & 4.5 & 0.214 \\
\hline Osteopenia $(n=122)$ & 16 & 39.0 & 46 & 57.7 & 60 & 53.6 & \\
\hline Osteoporosis $(n=66)$ & 4 & 9.8 & 15 & 18.8 & 47 & 42.0 & \\
\hline
\end{tabular}

B

\begin{tabular}{|c|c|c|c|c|c|c|c|}
\hline \multirow[t]{3}{*}{ Forearm } & \multicolumn{6}{|c|}{ Lumbar spine } & \multirow[t]{3}{*}{$\kappa$ value } \\
\hline & \multicolumn{2}{|c|}{ Normal } & \multicolumn{2}{|c|}{ Osteopenia } & \multicolumn{2}{|c|}{ Osteoporosis } & \\
\hline & $n$ & $\%$ & $n$ & $\%$ & $n$ & $\%$ & \\
\hline Overall: & 59 & 100 & 99 & 100 & 113 & 100 & \\
\hline Normal $(n=125)$ & 44 & 74.6 & 60 & 60.6 & 21 & 18.6 & 0.161 \\
\hline Osteopenia $(n=80)$ & 10 & 16.9 & 24 & 24.2 & 46 & 40.7 & \\
\hline Osteoporosis $(n=66)$ & 5 & 8.5 & 15 & 15.2 & 46 & 40.7 & \\
\hline$\leq 50$ years old: & 18 & 100 & 19 & 100 & 1 & 100 & \\
\hline Normal $(n=33)$ & 15 & 83.3 & 18 & 94.7 & 0 & & NA \\
\hline Osteopenia $(n=5)$ & 3 & 16.7 & 1 & 5.3 & 1 & 100 & \\
\hline Osteoporosis $(n=0)$ & 0 & & 0 & & 0 & & \\
\hline$>50$ years old: & 41 & 100 & 80 & 100 & 112 & 100 & \\
\hline Normal $(n=92)$ & 29 & 70.7 & 42 & 52.5 & 21 & 18.8 & 0.153 \\
\hline Osteopenia $(n=75)$ & 7 & 17.1 & 23 & 28.8 & 45 & 40.2 & \\
\hline Osteoporosis $(n=66)$ & 5 & 12.2 & 15 & 18.8 & 46 & 41.1 & \\
\hline
\end{tabular}

$\mathrm{C}$

\begin{tabular}{|c|c|c|c|c|c|c|c|}
\hline \multirow[t]{3}{*}{ Forearm } & \multicolumn{6}{|c|}{ Hip } & \multirow[t]{3}{*}{$\kappa$ value } \\
\hline & \multicolumn{2}{|c|}{ Normal } & \multicolumn{2}{|c|}{ Osteopenia } & \multicolumn{2}{|c|}{ Osteoporosis } & \\
\hline & $n$ & $\%$ & $n$ & $\%$ & $n$ & $\%$ & \\
\hline Overall: & 65 & 100 & 136 & 100 & 70 & 100 & \\
\hline Normal $(n=125)$ & 52 & 80.0 & 60 & 44.1 & 13 & 18.6 & 0.336 \\
\hline Osteopenia $(n=80)$ & 8 & 12.3 & 56 & 41.2 & 16 & 22.9 & \\
\hline Osteoporosis $(n=66)$ & 5 & 7.7 & 20 & 14.7 & 41 & 58.6 & \\
\hline$\leq 50$ years old: & 20 & & 14 & & 4 & & \\
\hline Normal $(n=33)$ & 19 & 95.0 & 11 & 78.6 & 3 & 75.0 & NA \\
\hline Osteopenia $(n=5)$ & 1 & 5.0 & 3 & 21.4 & 1 & 25.0 & \\
\hline Osteoporosis $(n=0)$ & 0 & & 0 & & 0 & & \\
\hline$>50$ years old: & 45 & & 122 & & 66 & & \\
\hline Normal $(n=92)$ & 33 & 73.3 & 49 & 40.2 & 10 & 15.2 & 0.326 \\
\hline Osteopenia $(n=75)$ & 7 & 15.6 & 53 & 43.4 & 15 & 22.7 & \\
\hline Osteoporosis $(n=66)$ & 5 & 11.1 & 20 & 16.4 & 41 & 62.1 & \\
\hline
\end{tabular}

$\%$ was represented by column percentage. 
Table III. Correlations between T-scores and type of beverage consumed

\begin{tabular}{|c|c|c|c|}
\hline \multirow[t]{2}{*}{ Beverage } & \multicolumn{3}{|c|}{ Biserial correlation coefficient $r$} \\
\hline & Lumbar spine & Hip & Forearm \\
\hline \multicolumn{4}{|l|}{ Overall: } \\
\hline Alcohol & 0.056 & 0.083 & $0.135^{*}$ \\
\hline Caffeine & $0.156^{*}$ & $0.226^{*}$ & $0.228^{*}$ \\
\hline \multicolumn{4}{|c|}{$\leq 50$ years old: } \\
\hline Alcohol & $0.325^{\star}$ & 0.124 & $0.330^{*}$ \\
\hline Caffeine & -0.017 & 0.179 & -0.017 \\
\hline \multicolumn{4}{|c|}{ > 50 years old: } \\
\hline Alcohol & 0.016 & 0.076 & 0.123 \\
\hline Caffeine & 0.104 & $0.178^{*}$ & $0.176^{\star}$ \\
\hline
\end{tabular}

*Indicates significant correlation between the two groups.

(alcohol and caffeine). Between any two of the three sites (lumbar spine vs. hip, lumbar spine vs. forearm, hip vs. forearm), there existed significant differences in $T$-scores (all $p<0.001$; Figure 2 ), yet BMD measurements within each pair of sites were well correlated (all $p<0.001$; Figure 3 ). As a result, a significant discrepancy was observed in the classification of osteoporosis at different locations, with hip and forearm showing the best correlation (Pearson's $r=0.627, p<0.001$, Figure $3 \mathrm{C}$ ). In addition, regarding the number of participants with the same diagnostic agreement in the three categories (normal, osteopenia, and osteoporosis) between lumbar spine and hip, lumbar spine and forearm, and hip and forearm, for participants over 50 years of age, hip and forearm showed the best agreement.

The use of caffeine or alcohol also correlated to varying degrees with $T$-scores in lumbar spine, hip and forearm. In the group $\leq 50$ years of age, lumbar spine and forearm $T$-scores were only associated with alcohol consumption (point biserial coefficient $r=0.325, p=0.046$ in lumbar spine and point biserial coefficient $r=0.330, p=0.043$ in forearm, respectively; Table III). In the group over 50 years of age, hip and forearm $T$-scores were only associated with caffeine consumption (point biserial coefficient $r=0.178, p=0.006$ in hip and point biserial coefficient $r=0.176$, $p=0.007$ in forearm, respectively; Table III). These results demonstrated that bone loss rates were site-dependent and were affected to varying degrees by the type of beverage consumed and age of the patient.

Based on the osteodensitometric definitions proposed by the WHO study group $[2,26]$, the diagnosis of either osteoporosis or osteopenia is made when a sufficiently low BMD is measured in one or more anatomic sites. Rachner et al.
[27] reported that the prevalence of osteoporosis increases with the number of scanned sites. A combination of lumbar spine and hip BMD data should be measured when diagnosing osteoporosis, even though this increases the prevalence of osteoporosis by $50 \%$ or more in perimenopausal women $[20,28]$. In clinical practice, the diagnosis of osteoporosis and the decision to initiate treatment are most commonly made by comparing BMD data of the lumbar spine to a normative database. Numerous prospective studies have reported that BMD measurements at various sites are equally effective in predicting future fractures [29-31]. According to their findings, measurement of lumbar spine BMD appears to provide adequate information to diagnose osteoporosis on the basis of bone mass measurements. However, several studies have shown considerable diagnostic disagreement between quantitative sonography of the calcaneus vs. DEXA scans of the spine and femur [32, 33]. Our finding of a significant difference between $T$-scores within the lumbar spine, hip, and forearm was in agreement with previous studies [21, 22, 34, 35]. Other workers have also found that BMD measurements at different anatomic sites varied depending on the sites studied [20, 36, 37].

Previous studies have shown that coffee and alcohol intake are risk factors for reduced BMD and increased osteoporotic fractures in women [13, 38]. In contrast, tea drinking has been associated with a higher BMD $[39,40]$ and a reduced risk of hip fracture [41, 42]. Our study was designed to prospectively determine whether beverage consumption had an influence on BMD measurements performed at different skeletal sites. The hip and forearm appeared to be the best site for predicting skeletal status based on our BMD measurements and correlated with caffeine consump- 
tion, especially in elderly Taiwanese females, while the lumbar spine was the least predictive site.

This was an important finding since both age and caffeine consumption are known risk factors for the development of osteoporosis. Breastfeeding has no deleterious effects and may confer an additional advantage for BMD in pre-menopausal women [43]. The rapid decline in estrogen production at menopause and an increased life span both contribute to the development of osteoporosis in elderly women [14]. With regards to the mechanism underlying the effect of caffeine consumption on BMD, considerable evidence supports a calciuretic effect $[13,14]$. Caffeine has also been shown to influence calcium metabolism by decreasing both vitamin $D$ receptor protein expression and alkaline phosphatase activity of osteoblasts [14]. In addition, the inverse relationship between caffeine intake and bone density found in our study has been evaluated in a report [13].

Hip fracture is the most devastating result of osteoporosis. Worldwide, the number of elderly is expected to double by 2040 , and the incidence of hip fractures is likely to become a substantial burden on public health systems due to the significant disability and high mortality rate associated with hip fracture as well as the cost of surgical treatment [44]. In the United States, for example, adjusted first-year costs associated with hip fracture for patients aged 65 years or older were US $\$ 15,196$ [45]. Thus, a better understanding of risk factors for developing osteoporosis may aid in preventing health issues, such as hip fractures and their related costs, particularly in our elderly Taiwanese women.

Our study had several limitations. We did not attempt to quantify total lifetime coffee consumption or take into consideration the type of coffee bean used, the brewing time, or the preparation method, all of which may affect the quantity of caffeine in the consumed drink [14]. In addition, the manner whereby coffee was consumed (e.g., decaffeinated, with or without milk or cream) was not considered. Also, cofounders such as consumption of other caffeinated beverages (soft drinks and energy drinks), other calcium sources such as milk, consumption of vitamin D, calcium supplements, health food supplements, magnesium, and physical activity and conditions that may affect calcium metabolism and the bone mineral density were not considered [2, 46]. Factors affecting calcium metabolism and bone deposition other than those directly affecting the bones, i.e., weight (obesity), and endocrine conditions such as diabetes were not considered in the analysis. Additional cofounders not considered included underlying diseases not mentioned by the patients such as duodenal ulcer and parathyroid disease. We also did not consider the effect of baseline BMD on the results. Other possible confounders commonly associated with coffee consumption (and which can contribute to the risk of osteoporosis) such as smoking and lack of exercise were not evaluated. In addition, we enrolled participants from open announcements in various departments and outpatient clinics, which may have led to some selection bias. Finally, DEXA of the lumbar spine can be extremely unreliable when calcification, sclerosis and osteophytes exist; however, we did not use quantitative computed tomography (QCT) as an alternative as it is expensive and, therefore, out of reach for most of our patients. In addition, it also results in higher radiation exposure compared with DEXA [21, 22].

A strength of this study involved providing lifestyle information on the effect of beverage consumption on BMD measurements at different skeletal sites in Taiwanese women stratified by age. The novelty of this study was the finding that bone loss rates for osteoporosis were site-specific and correlated with age and consumption of beverages, especially caffeine. The aim of this study was to determine the best site for BMD measurement based on T-scores, age, and beverage consumption when lumbar BMD measurements were not available. Our goal was not to change international algorithms, but merely to suggest that, in the face of significant spinal degeneration that may render lumbar BMD unreliable [21, 22], the other two sites for BMD should be used (i.e., hip and forearm), particularly in elderly Taiwanese women who drink caffeine. We still, however, measure all three sites (lumbar spine, forearm and hip) when performing each DEXA scan in our hospital.

In conclusion, BMD measurements at the hip and forearm correlated with caffeine consumption in elderly Taiwanese women. This is an important finding since age and caffeine consumption are known risk factors for the development of osteoporosis.

\section{Acknowledgments}

This study was funded by Taoyuan Armed Forces General Hospital Grant 10226 and TSGH IRB No: TY 101-17.

\section{Conflict of interest}

The authors declare no conflict of interest.

\section{References}

1. Boutroy S, Bouxsein ML, Munoz F, Delmas PD. In vivo assessment of trabecular bone microarchitecture by high-resolution peripheral quantitative computed tomography. J Clin Endocrinol Metab 2005; 90: 6508-15. 
2. World Health Organization. Prevention and Management of Osteoporosis: Report of a WHO Scientific Group (Technical Report Series, No. 921) (WHO Technical Report Series) 2003.

3. Damilakis J, Adams JE, Guglielmi G, Link TM. Radiation exposure in X-ray-based imaging techniques used in osteoporosis. Eur Radiol 2010; 20: 2707-14.

4. Kanis JA, McCloskey EV, Johansson H, Oden A, Melton III LJ, Khaltaev N. A reference standard for the description of osteoporosis. Bone 2008; 42: 467-75.

5. Adams JE. Dual-energy X-ray absorptiometry. In: Osteoporosis and Bone Densitometry Measurements. Guglielmi G (ed.). Springer, New York 2013; 101-22.

6. Du F, Qiukui H, Birong D, et al. Association of osteoporotic fracture with smoking, alcohol consumption, tea consumption and exercise among Chinese nonagenarians/centenarians. J Nutr Health Aging 2011; 15: 327-31.

7. Muraki S, Yamamoto S, Ishibashi $\mathrm{H}$, et al. Diet and lifestyle associated with increased bone mineral density: cross-sectional study of Japanese elderly women at an osteoporosis outpatient clinic. J Orthop Sci 2007; 12: 317-20.

8. Sheng J, Qu X, Zhang X, et al. Coffee, tea, and the risk of hip fracture: a meta-analysis. Osteoporos Int 2014; 25: 141-50.

9. Devine A, Hodgson JM, Dick IM, Prince RL. Tea drinking is associated with benefits on bone density in older women. Am J Clin Nutr 2007; 86: 1243-7.

10. Singh MAF. Exercise, nutrition and managing hip fracture in older persons. Curr Opin Clin Nutr Metab Care 2014; 17: 12-24.

11. Yin J, Winzenberg T, Quinn S, Giles G, Jones G. Beverage-specific alcohol intake and bone loss in older men and women: a longitudinal study. Eur J Clin Nutr 2011; 65: 526-32.

12. Tseng HC, Wang CJ, Cheng SH, et al. Tea-drinking habit among new university students: associated factors. Kaohsiung J Med Sci 2013; 30: 98-103.

13. Hernandez-Avila M, Colditz GA, Stampfer MJ, Rosner B, Speizer FE, Willett WC. Caffeine, moderate alcohol intake, and risk of fractures of the hip and forearm in middle-aged women. Am J Clin Nutr 1991; 54: 157-63.

14. Lee DR, Lee J, Rota $M$, et al. Coffee consumption and risk of fractures: a systematic review and dose-response meta-analysis. Bone 2014; 63: 20-8.

15. Haentjens P, Magaziner J, Colón-Emeric CS, et al. Metaanalysis: excess mortality after hip fracture among older women and men. Ann Intern Med 2010; 152: 380-90.

16. Walker-Bone K, D’Angelo S, Syddall H, et al. Exposure to heavy physical occupational activities during working life and bone mineral density at the hip at retirement age. Occup Environ Med 2014; 71: 329-31.

17. Tamaki J, Iki M, Fujita $Y$, et al. Impact of smoking on bone mineral density and bone metabolism in elderly men: the Fujiwara-kyo Osteoporosis Risk in Men (FORMEN) study. Osteoporos Int 2011; 22: 133-41.

18. Senel K, Baykal T, Seferoglu B, et al. Circulating vascular endothelial growth factor concentrations in patients with postmenopausal osteoporosis. Arch Med Sci 2013; 9: 709-12.

19. Anagnostis P, Vakalopoulou S, Charizopoulou M, et al. Is there any association between leptin levels and bone mineral density in haemophiliac men? Arch Med Sci 2013; 9: 459-65.

20. Chantler S, Dickie K, Goedecke J, et al. Site-specific differences in bone mineral density in black and white premenopausal South African women. Osteoporos Int 2012; 23: 533-42.

21. Link TM. Axial and peripheral QCT. In: Osteoporosis and Bone Densitometry Measurements. Guglielmi G (ed.). Springer-Verlag, Berlin 2013; 123-34.

22. Malluche HH, Davenport DL, Cantor T, Monier-Faugere MC. Bone mineral density and serum biochemical predictors of bone loss in patients with CKD on dialysis. Clin J Am Soc Nephrol 2014; 9: 1254-62.

23. Scafoglieri A, Provyn S, Wallace J, et al. Whole Body Composition by Hologic QDR 4500/A DXA: System Reliability versus User Accuracy and Precision, Applications and Experiences of Quality Control, Prof. Ognyan Ivanov (ed.), ISBN: 978-953-307-236-4, InTech, 2011; 45-62.

24. IOF One-Minute Risk http://www.iofbonehealth.org/ date accessed: November 2014.

25. Lang, TA, Secic M. How to report statistics in medicine: annotated guidelines for authors, editors, and reviewers. $2^{\text {nd }}$ ed. Sheridan Press, Hanover (PA) 2006.

26. World Health Organization. Assessment of fracture risk and its application to screening for postmenopausal osteoporosis. Report of a WHO Study Group. World Health Organization technical report series 1994; 843: 1-129.

27. Rachner TD, Khosla S, Hofbauer LC. Osteoporosis: now and the future. Lancet 2011; 377: 1276-87.

28. Abrahamsen B, Hansen T, Jensen LB, Hermann A, Eiken P. Site of osteodensitometry in perimenopausal women: correlation and limits of agreement between anatomic regions. J Bone Miner Res 1997; 12: 1471-9.

29. Melton LJ, Atkinson EJ, O'Fallon WM, Wahner HW, Riggs BL. Long-term fracture prediction by bone mineral assessed at different skeletal sites. J Bone Miner Res 1993; 8: 1227-33.

30. Wasnich RD, Ross PD, Davis JW, Vogel JM. A comparison of single and multi-site BMC measurements for assessment of spine fracture probability. J Nucl Med 1989; 30: 1166-71.

31. Namwongprom S, Rojnastein S, Mangklabruks A, Soontrapa S, Taya P, Ongphiphadhanakul B. Discrepancy of left and right hip bone mineral density (BMD) in Thai women: diagnostic agreement and misclassification. Ann Nucl Med 2012; 26: 787-93.

32. Krestan C, Grampp S, Resch-Holeczke A, Henk C, Imhof H, Resch $H$. Diagnostic disagreement of imaging quantitative sonography of the calcaneus with dual X-ray absorptiometry of the spine and femur. AJR 2001; 177 : 213-6.

33. Grampp S, Henk C, Fuerst T, et al. Diagnostic agreement of quantitative sonography of the calcaneus with dual X-ray absorptiometry of the spine and femur. AJR 1999; 173: 329-34.

34. Lai K, Rencken M, Drinkwater BL, Chesnut III CH. Site of bone density measurement may affect therapy decision. Calcif Tissue Int 1993; 53: 225-8.

35. Pouilles J, Tremollieres F, Ribot C. Spine and femur densitometry at the menopause: are both sites necessary in the assessment of the risk of osteoporosis? Calcif Tissue Int 1993; 52: 344-7.

36. Wilson J, Bonner T, Head M, Fordham J, Brealey S, Rangan $A$. Variation in bone mineral density by anatomical site in patients with proximal humeral fractures. J Bone Joint Surg Br 2009; 91: 772-5.

37. Cui LH, Shin MH, Kweon SS, et al. Relative contribution of body composition to bone mineral density at different sites in men and women of South Korea. J Bone Miner Metab 2007; 25: 165-71. 
38. Cummings SR, Nevitt MC, Browner WS, et al. Risk factors for hip fracture in white women. N Engl J Med 1995; 332: 767-74.

39. Wu CH, Yang YC, Yao WJ, Lu FH, Wu JS, Chang CJ. Epidemiological evidence of increased bone mineral density in habitual tea drinkers. Arch Intern Med 2002; 162: 1001-6.

40. Chen Z, Pettinger M, Ritenbaugh C, et al. Habitual tea consumption and risk of osteoporosis: a prospective study in the women's health initiative observational cohort. Am J Epidemiol 2003; 158: 772-81.

41. Kanis J, Johnell O, Gullberg B, et al. Risk factors for hip fracture in men from Southern Europe: the MEDOS study. Osteoporos Int 1999; 9: 45-54.

42. Johnell O, Gullberg B, Kanis JA, et al. Risk factors for hip fracture in European women: the MEDOS study. J Bone Miner Res 1995; 10: 1802-15.

43. Canal-Macias ML, Roncero-Martin R, Moran JM, LavadoGarcia JM, del Carmen Costa-Fernandez M, PedreraZamorano JD. Increased bone mineral density is associated with breastfeeding history in premenopausal Spanish women. Arch Med Sci 2013; 9: 703-8.

44. Qu B, Ma Y, Yan M, et al. The economic burden of fracture patients with osteoporosis in western China. Osteoporos Int 2014; 25: 1853-60.

45. Shi N, Foley K, Lenhart G, Badamgarav E. Direct healthcare costs of hip, vertebral, and non-hip, non-vertebra fractures. Bone 2009; 45: 1084-90.

46. Slevin MM, Allsopp PJ, Magee PJ, et al. Supplementation with calcium and short-chain fructo-oligosaccharides affects markers of bone turnover but not bone mineral density in postmenopausal women. J Nutr 2014; 144 : 297-304. 